\title{
A Systematic Characterization of Cognitive Techniques for Learning from Textual and Pictorial Representations
}

\author{
Rolf Ploetzner ${ }^{1}$, Richard Lowe ${ }^{2} \&$ Sabine Schlag ${ }^{3}$ \\ ${ }^{1}$ Institute of Media in Education, University of Education, Freiburg, Germany \\ ${ }^{2}$ School of Education, Curtin University, Bentley WA, Australia \\ ${ }^{3}$ School of Education, University of Wuppertal, Wuppertal, Germany \\ Correspondence: Rolf Ploetzner, Institute of Media in Education, University of Education, Kunzenweg 21, 79117 \\ Freiburg, Germany. Tel: 49-761-682-900. E-mail: rolf.ploetzner@ph-freiburg.de
}

\author{
Received: February 27, 2013 Accepted: March 13, $2013 \quad$ Online Published: May 2, 2013 \\ doi:10.5539/jel.v2n2p78 URL: http://dx.doi.org/10.5539/jel.v2n2p78
}

This research was supported by the German Academic Exchange Service (DAAD) and the Australian Technology Network (ATN) within the "Joint Research Cooperation Scheme" and by the Deutsche Forschungsgemeinschaft (DFG) under contract PL 224/17-1.

\begin{abstract}
Pictorial representations can play a pivotal role in both printed and digital learning material. Although there has been extensive research on cognitive techniques and strategies for learning from text, the same cannot be said for static and dynamic pictorial representations. In this paper we propose a systematic characterization of cognitive learning techniques that is founded on both theoretical and empirical research. The characterization relates the learning techniques to classes of cognitive processes as well as to textual and pictorial representations. We show how successful strategies for learning from both plain text and illustrated text are covered by the characterization. We also exemplify how the construction of new strategies for pictorial representations can be informed by the characterization.
\end{abstract}

Keywords: pictorial representations, textual representations, cognitive processes, learning techniques, learning strategies

\section{Introduction}

In recent years, digital technology has revolutionized the production and use of educational materials. Firstly, conventional resources such as textbooks have become far more profusely illustrated than before due to the extensive cost savings made possible by the switch from analogue to digital production methods (cf. Pettersson, 2008). Secondly, digitization of information has greatly facilitated the seamless combination of varied forms of learning media and allowed these combinations to be interactive. A feature of the resulting multimedia learning environments is that they are not restricted to using static pictures only - dynamic graphics such as animations now play a pivotal role in these resources.

These fundamental changes in production and presentation in turn prompted a reconsideration of the way comprehension and learning processes were theorized. For instance, the concept of literacy was traditionally confined - as the term implies - to the production and comprehension of texts, i.e., verbal representations (e.g., Street, 1984). However some more recent semiotic perspectives have sought to expand the concept of literacy to encompass other ways of representing information including pictorial and interactive portrayals (e.g., Doelker, 1997; Kress, 2003; Kress \& van Leeuwen, 2006; OECD, 2000). An alternative view (e.g., de Vries \& Lowe, 2010) maintains that the term graphicacy rather than literacy should be used for pictorial materials because of deep seated differences between the sign systems of textual and pictorial representations (cf. Schnotz, 2001). Furthermore, psychological theories of learning from textual representations (e.g., Kintsch \& van Dijk, 1978) were broadened to include learning from combinations of texts and pictures (e.g., Mayer, 2009; Schnotz \& Bannert, 2003). Last but not least, a considerable body of research on multimedia learning aims to design combinations of textual and pictorial representations in such a way that students' processing of information is facilitated (for overviews see Clark \& Mayer, 2008; Mayer, 2005a). The design of representations alone, 
however, cannot guarantee effective learning. Rather, it is only one side of the coin. The other side involves the cognitive processes that students actually apply to the learning material. These processes are manifested in the techniques and strategies that students use when learning from text and pictures.

According to Streblow and Schiefele (2006), a learning strategy can be understood as “... a sequence of efficient learning techniques, which are used in a goal-orientated and flexible way, for which processing is increasingly automated, but which are nevertheless consciously applied"' (p. 353; translation by the authors). Learning techniques are hence the individual components that are collectively employed as an overall learning strategy. Examples of learning techniques include highlighting key phrases in a text, or marking important regions in a picture. Learning techniques constitute a learning strategy only when a number of them are coordinated in a goal-oriented way. The aim of applying a learning strategy is to induce, support, and sustain effective learning processes.

Three broad classes of learning strategies are typically distinguished (e.g., Streblow \& Schiefele, 2006): cognitive strategies, metacognitive strategies, and resource strategies. The aim of cognitive strategies is to foster effective primary information processing, whereas metacognitive strategies focus on the super-ordinate level of the planning, monitoring and regulation of cognitive processes. In contrast to these internally focused strategies, resource strategies focus on establishing supportive external learning environments (e.g., ensuring access to learning resources, avoiding distractions, etc.). The present paper concentrates on cognitive learning strategies such as organizational strategies, elaboration strategies, and rehearsal strategies (cf. Weinstein \& Mayer, 1986; Wittrock, 1974, 1989) and their component techniques.

Research on cognitive techniques and strategies for learning from textual representations has a long and extensive tradition that reaches back to the influential work of Robinson (1946). In stark contrast, techniques and strategies for learning from static and dynamic pictorial representations remain relatively neglected by researchers. This probably explains why techniques and strategies for learning from pictorial representations are rarely taught to students at school or pre-service teacher students at the university (cf. Kremling, 2008). The potentially damaging consequences of this neglect with respect to pictorial representations are exacerbated by educators who mistakenly assume that pictures are not only intrinsically beneficial but also self-explanatory (e.g., Lieber, 2008). Further, students may experience "illusions of understanding" when asked to learn from pictures (cf. Salomon, 1983, 1984) but not actually comprehend. Research has demonstrated that students can have severe difficulties in understanding static (e.g., Weidenmann, 1989, 2006) and dynamic pictures (e.g., Lowe, 2003, 2004, 2008; Ploetzner, Bodemer, \& Neudert, 2008; Ploetzner, Lippitsch, Galmbacher, Heuer, \& Scherrer, 2009). Thus, while present-day picture-rich learning materials used in schools and universities place many and varied demands on the students' cognitive processes, students may lack the cognitive techniques and strategies needed to cope successfully with these requirements. A central goal of this paper is to provide a systematic and principled framework designed to help researchers construct additional cognitive techniques and strategies for learning from pictorial representations that complement those already developed for textual representations.

This paper is made up of four main parts. In the first part, we note that while extensive research on cognitive techniques and strategies for learning from textual representations has been conducted, research on techniques and strategies for learning from static and dynamic pictorial representations is still sparse. In the second part, we summarize important theoretical models of learning from textual and pictorial representations. In the third part, we posit a systematic characterization of cognitive techniques for learning from textual and pictorial representations. The characterization builds on both (a) current theories and models of learning from different representations and (b) existing research on cognitive learning techniques and strategies. It makes evident broad deficits in the research on cognitive techniques for learning from pictorial representations. In the fourth part, we show how successful strategies for learning from text-based representations are covered by the characterization as well as how the generation of new techniques and strategies for pictorial representations can be informed by the characterization. The paper concludes by suggesting possible directions for future research on cognitive techniques and strategies for learning, particularly with respect to pictorial representations.

\section{Previous Research on Cognitive Techniques and Strategies for Learning from Textual and Pictorial Representations}

Early research on learning strategies was carried out at a time when written text was the dominant form of information representation. Unsurprisingly, it focused on textual representation with the main objective being to identify how successful and less successful learners differed in their strategic behavior during learning. Marton and Säljö (1984), for example, empirically identified two different approaches to learning from texts. They distinguished between a surface level approach, such as the repeated reciting of text in order to remember it, and 
a deep level approach, in which the text information is processed more intensively and elaborated in order to comprehend it. Successful learners were found to favor deep level approaches. Similar observations with respect to the depth of text processing have been made in other studies such as those by Dornisch, Sperling and Zeruth (2011), Pask (1976), Schlag, Florax and Ploetzner (2007), and Svensson (1977).

Consistent with these findings, text learning strategies have been devised that aim to induce and promote beneficial elaboration and comprehension processes. For instance, building on the early work of F. P. Robinson (1946), Thomas and H. A. Robinson (1972) devised the well-known PQ4R-Method (Preview, Question, Read, Reflect, Recite, Review) that structures learning from text by means of six steps: (1) Survey the material to get a general overview (Preview), (2) formulate questions about the text (Question), (3) read the text thoroughly while keeping the formulated questions in mind (Read), (4) reflect on the text by relating the information to prior knowledge and formulating examples (Reflect), (5) answer the questions by giving an account of the text in one's own words (Recite), and (6) try to recall or summarize the information that has been read without looking at the text (Review). Further examples of strategies for learning from texts are MURDER (Mood, Understanding, Recall, Digest, Expanding, Review) from Dansereau et al. (1979) and REDUTEX (Reduce Text) from Friedrich (1995).

Current research on learning strategies is still geared almost exclusively to learning from texts (for overviews see Artelt, 2000; Gambrell, Morrow \& Pressley, 2007; Mandl \& Friedrich, 1992, 2006; Pressley \& Harris, 2006). This is despite the fact that text no longer occupies the dominant position it once did in the educational landscape. Instead, today's learning materials frequently contain a substantial proportion of pictures, very often more than the amount of text. In order to provide a form of support paralleling that available for text-only materials, researchers such as Larson et al. (1986), Schlag and Ploetzner (2009, 2011), and Seufert (2009) have proposed strategies for learning from illustrated texts. For instance, the strategy employed by Schlag and Ploetzner (2009, 2011 ) is made up of a sequence of learning techniques that aim to address not only the text and pictorial components, but also the relations between these different types of representation. Two experimental studies showed that students who took advantage of the strategy exhibited significantly larger learning gains than students who wrote a summary of the learning material. Research by Metz and Wichert (2009) also showed that a similar strategy for learning from illustrated text produced beneficial outcomes.

With respect to facilitating learning from static pictures, only single, isolated learning techniques - as opposed to learning strategies - have been proposed and empirically evaluated. For example, in order to encourage learners to process pictures more deeply, both Salomon (1984) and Weidenmann (1989) asked learners to pay special attention to the pictures while orienting themselves towards the learning material. Peeck (1994) challenged learners to create pictures of their own and asked learners to answer questions about the target pictures (see also Weidenmann, 1994). Weidenmann (1988) prompted learners to compare different pictures. Ainsworth and Loizou (2003) encouraged learners to explain the pictures to themselves. Although each of these individual techniques may have its own value in helping to support picture comprehension, on their own they do not constitute a comprehensive learning strategy.

For dynamic pictures such as animations and simulations, research on learning strategies and learning techniques is particularly sparse. De Koning, Tabbers, Rikers and Paas (2010) asked learners to explain an animation to themselves. Hegarty, Kriz and Cate (2003) asked learners to express verbally relations between verbal and pictorial information presented in an animation. Moreno and Valdez (2005) supported learning from animation by directing low-achievers to organize segments of an animation into an appropriate sequence. High-achievers, in contrast, benefitted most from splitting an animation into meaningful segments by themselves. Schmidt-Weigand (2005) encouraged learners to stop an animation when the display showed important information and then analyze the display's components as well as their relations. Gane and Catrambone (2006) posed questions asking learners for information about various aspects of the animated process. Taking advantage of de Jong's (2005) concept of guided discovery learning, Huk and Ludwigs (2009) encouraged learners to self-explain an animated simulation.

Until recently, research on learning from dynamic pictures also focused exclusively on individual learning techniques rather than investigating comprehensive learning strategies. However, Kombartzky, Ploetzner, Schlag and Metz (2010) have proposed a first strategy for fostering deep level learning from animation. The strategy encompasses a sequence of eight different techniques for learning from narrated animations. In two experimental studies, students who made use of the strategy learned significantly more than students who wrote a summary of the animated process. 


\section{Theories of Learning from Textual and Pictorial Representations}

Current techniques and strategies for learning from textual and pictorial representations share an underlying objective: They all aim to foster deep level learning by inducing fundamental cognitive processes such as the identification, selection, organization, elaboration, transformation, and integration of information. Unsurprisingly, such processes also play a pivotal role in theories and models of learning from textual and pictorial representations. Influential examples are Kintsch and van Dijk's (1978) theory of text comprehension, Wittrock's $(1974,1989)$ theory of generative learning as well as the application of these theories to multimedia material by Mayer (2009; see also Mayer, 2005b) and Schnotz and Bannert (2003; see also Schnotz, 2005).

In his theory of multimedia learning, Mayer (2009) characterizes multimedia material as combinations of spoken or printed texts and static or dynamic pictures. In accord with Atkinson and Shiffrin (1971) and Baddeley (1986), Mayer (2009) assumes that the human memory is divided into three sub-systems: the sensory registers, working memory, and long-term memory. Mayer (2009) formulates three basic assumptions concerning the working memory. First, the working memory is made up of both an auditory-verbal and a visual-pictorial channel (Baddeley, 1986; Paivio, 1986). Second, the capacity of the working memory is limited, i.e., only a limited amount of information can be processed simultaneously (Atkinson \& Shiffrin, 1971; Baddeley, 1986). Third, successful learning from different representations requires an active processing and integration of the information presented (Wittrock, 1989).

Mayer (2009) regards four types of cognitive processes as being important to successful multimedia learning: the selection, transformation, organization, and integration of information. The first step when learning from multimedia is to select relevant words from the available texts and relevant graphic entities from the available pictures. Subsequently, mental images may be transformed into auditory-verbal information by means of internal verbalizations and auditory-verbal information may be transformed into mental images by means of internal visualizations. Next, the material needs to be further processed in order to gain an understanding of the information and to retain it in long-term memory. For this purpose, it is necessary to organize the selected information. At first this takes place separately for textual and pictorial information so that both a verbal model and a pictorial model is constructed. Thereafter, in order to store the information in the long-term memory, both the verbal and pictorial models, as well as already existing knowledge must be integrated by relating corresponding elements to each other.

Models of multimedia learning are more concerned with how text-picture combinations are processed than with how the individual textual and pictorial components themselves are processed. Finer detail about how individual representations are processed can be found in the work of researchers such as Kintsch and van Dijk (1978; see also Kintsch, 1998) who provide a comprehensive characterization of text processing. However, the literature on how graphics are processed is much less extensive than it is for text. With respect to the comprehension of graphics such as pictures and diagrams, Weidenmann (1988), Pinker (1990), and Winn (1993) have made significant theoretical contributions. Weidenmann (1988) distinguishes between two different modes of understanding: ecological understanding and indicatorial understanding. Ecological understanding concerns the recognition of entities and scenes in a picture. In order to accomplish this task, Weidenmann (1988) assumes that learners apply the same processes to a picture that they do to visual perceptions of the natural environment. Depictive codes in the picture assist the learner in constructing the appropriate surface structures. Examples of depictive codes are the use of perspectives and colors. Indicatorial understanding, in contrast, concerns the identification and comprehension of visual arguments in a picture. In order to achieve this goal, the learner needs to interpret directive codes in the picture as indicators for arguments. Examples of directive codes are the use of accentuations, comparisons, enlargements, and directing symbols such as arrows.

Numerous principles for the design of visual arguments have been developed (e.g., Tufte, 2005). Because instructional pictures invariably require the learner to extract visual arguments, they demand not only ecological but also indicatorial understanding. Many learners, however, process instructional pictures only ecologically (i.e., they apply a surface level approach) and not indicatorially (i.e., they do not make use of a deep level approach; cf. Weidenmann, 1989, 2006).

Weidenmann (1988) further assumes that two different types of processes are essential for the understanding of instructional pictures: pre-attentive processes and attentive processes. While pre-attentive processes are made up of procedures that are automatically executed within fractions of a second and without conscious control, attentive processes encompass procedures that are consciously and intentionally executed over longer periods of time. By means of attentive processes, learners systematically search for information and draw conclusions from 
the acquired information. Whereas ecological understanding might be accomplished through pre-attentive processes, indicatorial understanding typically requires additional attentive processes.

Weidenmann (1988) focuses on learning from realistic and schematic pictures (see also Weidenmann, 1994) in which there is a high degree of structural analogy between the pictures and the represented objects. Pinker (1990), in contrast, has proposed a model of how learners understand abstract graphics such as line diagrams, bar charts, and pie charts for which the structural correspondences are less direct. Like Weidenmann (1988), Pinker (1990) also distinguishes between pre-attentive and attentive processes when learning from a diagram. Perceptually-driven pre-attentive processes enable learners to first identify the basic elements of a diagram such as forms, positions, inclines, and angles. These elements are organized as perceptual groups which form an analog representation known as a visual array. Such visual arrays are subsequently encoded as symbolic representations in working memory.

Pinker contends that perceived elements and their spatial relations are described by means of propositions within these representations. In the next step, the propositional representation is matched against schemata of diagrams in long-term memory. The schema that corresponds best to the propositional representation becomes instantiated with the information contained in the propositional representation. A schema is composed of both declarative and procedural knowledge about a specific type of diagram. While declarative knowledge encodes information about the geometrical features of a diagram, procedural knowledge represents how certain information can be inferred from a diagram. Finally, the instantiated schema is drawn upon in order to form conceptual relations, to initiate the retrieval of additional information from the diagram, and to infer information not explicitly represented in the diagram. Pinker's (1990) model emphasizes the need for learners to acquire schemata of diagrams in order to be able to process diagrams effectively and efficiently.

Winn (1993) also focuses on how viewers process diagrammatic information. While acknowledging that both pre-attentive and attentive processes are involved in extracting information from diagrams, he gives particular emphasis to the role of perception. In Winn's account, pre-attentive processing is broken down into two complementary processes - discrimination in which a diagram's constituent symbols are singled out as individual entities, and configuration in which those entities are grouped into larger assemblies. Perceptual issues such as visual contrast and the emergent properties of symbols are identified as fundamental to readers' discrimination and configuration of the depiction's component entities. These visual processes are not typically given commensurate consideration in accounts of text processing which tend to have a largely cognitive orientation.

For diagram search to be effective, the contribution of bottom-up pre-attentive aspects such as perceptual salience must be complemented by top-down influences derived from knowledge of both (i) the symbol system together with its diagrammatic conventions, and (ii) the depicted content. These attentive contributions help guide diagram readers as to what they should look for and where they should look for it. In addition to supporting the selection of information, attentive processing on the basis of content knowledge schemas can help readers to organize the information they select into meaningful assemblies or chunks.

Winn also suggests that the process of searching for information in diagrams can be cumulative in that multiple sweeps may need to be made in order to achieve a goal. The strategies that a reader uses to scan a diagram are influenced by the nature of that goal and the reading conventions assumed to be appropriate for the particular display's structure. Although some strategies (such as partitioning a display into sections) are applicable across different types of diagram, their effectiveness in facilitating learning can depend on the reader's knowledge of the depicted content.

The most distinctive difference between dynamic representations such as animations and static representations is their temporal structure. However, research on how learners actually process animated displays has not kept pace with the rapidly expanding educational uses of animation. Systematic exploration of perceptual and cognitive processing factors that can influence learning from animation is a relatively recent development. A key contribution in this area was made by Kriz and Hegarty (2007) who identified the importance of both bottom-up and top-down influences in learning from animation. The interplay of these two influences is also a central pillar of the Animation Processing Model (APM) which is particularly concerned with how dynamics influence information extraction and integration (Lowe \& Boucheix, 2008, 2011). The APM characterizes learning from animation in terms of five processing phases with a progression from a bottom-up to a top-down emphasis: (1) localized perceptual exploration, (2) regional structure formation, (3) global characterization, (4) functional differentiation, and (5) mental model consolidation. These phases involve iterative and cumulative processing of the externally presented dynamic portrayal that, if successful, results in the learner constructing a high quality mental model of the subject matter depicted in the animation. 
During localized perceptual exploration, the learner uses largely perceptually-based processing to parse the continuous flux of an animation into differentiated components. This parsing results in a set of event units that are the basis for the subsequent processing operations. Each event unit consists of an entity depicted in the animation plus its associated behavior. The process of isolating event units from the animation provides the building blocks from which a mental model of the to-be-learned subject matter will be constructed.

During regional structure formation, the learner uses aspects such as gestalt relations between neighboring event units to connect this parsed material into small regional clusters of activity. However, the resulting dynamic micro-chunks are distributed across the animation in spatially and temporally separated locations. In order to develop a coherent internal representation from the individual dynamic micro chunks, the process of global characterization bridges these isolated islands of activity into broader relational structures.

A key process involved in this inter-linking is the establishment of domain general causal chains that are not based on the specific functionality of the referent subject matter. The process of functional differentiation introduces such functionality by applying domain specific background knowledge to the relationships previously established and reinterpreting them where necessary. This allows the causal chains to be characterized in terms of the specific functional purpose of the content depicted in the animation.

Finally, during mental model consolidation flexibility is introduced into the mental model by extending the functionality of the depicted system to cover a variety of operational requirements. This gives the learner the capacity to deal with the behavior of the system in unfamiliar circumstances, such as those encountered in problem solving situations.

Although the five phases are described here sequentially, this is not meant to imply that they will necessarily occur in this neat linear fashion during learning. Rather, a recursive alternation between phases would typically be expected as the learner progressively works with the animated material. Further, the quality of the mental model ultimately developed would very much depend on the extent of an individual learner's domain specific background knowledge regarding the depicted content. Without such knowledge, the learner may have difficulty in extracting the required raw material from an animation and then integrating it into a coherent and functionally effective whole.

Various broad classes of cognitive - as well as visual - processes are addressed in many theoretical accounts of learning from textual and pictorial representations (e.g., Kintsch, 1998; Mayer, 2009; Schnotz \& Bannert, 2003; Wittrock, 1974, 1989): (1) orientation and overview, (2) comprehensive scanning, (3) identification and selection of information, (4) organization of information, (5) elaboration, transformation and integration of information, and (6) rehearsal. The first three classes of cognitive processes are concerned with both exploring the information space and selecting informational units. The fourth and fifth classes address the cognitive processes involved in the generation of structure and meaning. The sixth class, rehearsal, focuses on cognitive processes that concern the remembering of information such as systematic recapitulation and mnemonic techniques.

\section{A Systematic Characterization of Cognitive Techniques for Learning from Textual and Pictorial Representations}

Although theoretical accounts of learning from textual and pictorial representations suggest that the classes of cognitive processes described above form the foundation for understanding textual and pictorial representations, the preceding summary of research on learning techniques and strategies indicates that these processes can be induced in a variety of different ways. On the basis of (a) the learning techniques and strategies reported in the literature, (b) the theories and models of learning from textual and pictorial representations described above, and (c) our own analyses, we developed a systematic characterization of learning techniques (cf. Table 1) that deals with all major classes of representations: learning from texts, pictures, diagrams, combinations of texts and graphics, and animations. The characterization brings together these different types of representations within a common framework in order to provide a unified approach to areas that until now have lacked cohesion. In doing so, it highlights significant gaps that exist in research and practice with respect to pictorial representations.

The rows of Table 1 are organized according to the six broad classes of cognitive processes as described above. The columns are arranged according to the major classes of representations. Each cell shows learning techniques that aim to induce the corresponding cognitive process and that are applicable to the corresponding representation. The numbers in brackets attached to the techniques refer to research that has theoretically conceptualized or empirically investigated the corresponding techniques. The complete references are provided at the end of the paper. 
Because the main concern of this paper is with learning from pictorial representations, in Table 1 the references to research on techniques for learning from text are selective. We acknowledge that far more research on techniques for learning from text has been conducted (for overviews see Artelt, 2000; Gambrell, Morrow \& Pressley, 2007; Mandl \& Friedrich, 1992, 2006; Pressley \& Harris, 2006). However, we are unaware of further research on cognitive techniques for learning from static and dynamic pictorial representations, i.e., research that has theoretically conceptualized or empirically investigated such techniques. With respect to learning material that comprises pictorial representations, most of the techniques that have been suggested are intended to facilitate learning from illustrated texts. In accordance with current theories and models of multimedia learning (e.g., Mayer, 2009; Schnotz, 2005), many of these techniques encourage the students to interrelate the textual and pictorial representations structurally as well as semantically.

In those cases where we are unaware of research on specific techniques for learning from static and dynamic pictorial representations, we formulated such techniques on the basis of current theories and models of how learners process pictorial representations. For instance, various researchers suggest that a text should be read carefully and completely after overviewing it (e.g., Dansereau et al., 1997; Robinson, 1946; Thomas \& Robinson, 1972). We are not aware of research that specifies comparable techniques for learning from animations. However, research conducted by Lowe $(1999,2003,2004$, 2008) demonstrates that learners easily miss important entities in the pictorial display of an animation. Therefore, in Table 1 we formulated two techniques that concern the cognitive process of comprehensive scanning while learning from animations: (1) scan the animation's display and (2) if the animation is narrated, listen to the animation's narration systematically and completely.

In developing Table 1, special emphasis was placed on abstracting generic approaches that are super-ordinate to the individual techniques specific to certain kinds of representation (cf. the second column in Table 1). These abstracted approaches lie in a conceptual space between (a) the fundamental cognitive processes they aim to induce, and (b) the representation-specific techniques associated with particular representation types or their combinations. They express the overarching purpose that is manifested in the form of different representation-specific techniques.

In order to explore the potential of our characterization of cognitive learning techniques, in the next section we illustrate how successful strategies for learning from text as well as from illustrated text are covered by the characterization. We also show how the characterization can be used for constructing a new strategy for learning from animation.

Table 1. Cognitive learning techniques categorized according to cognitive processes and representations: The numbers in brackets refer to research that has theoretically conceptualized or empirically evaluated the corresponding techniques

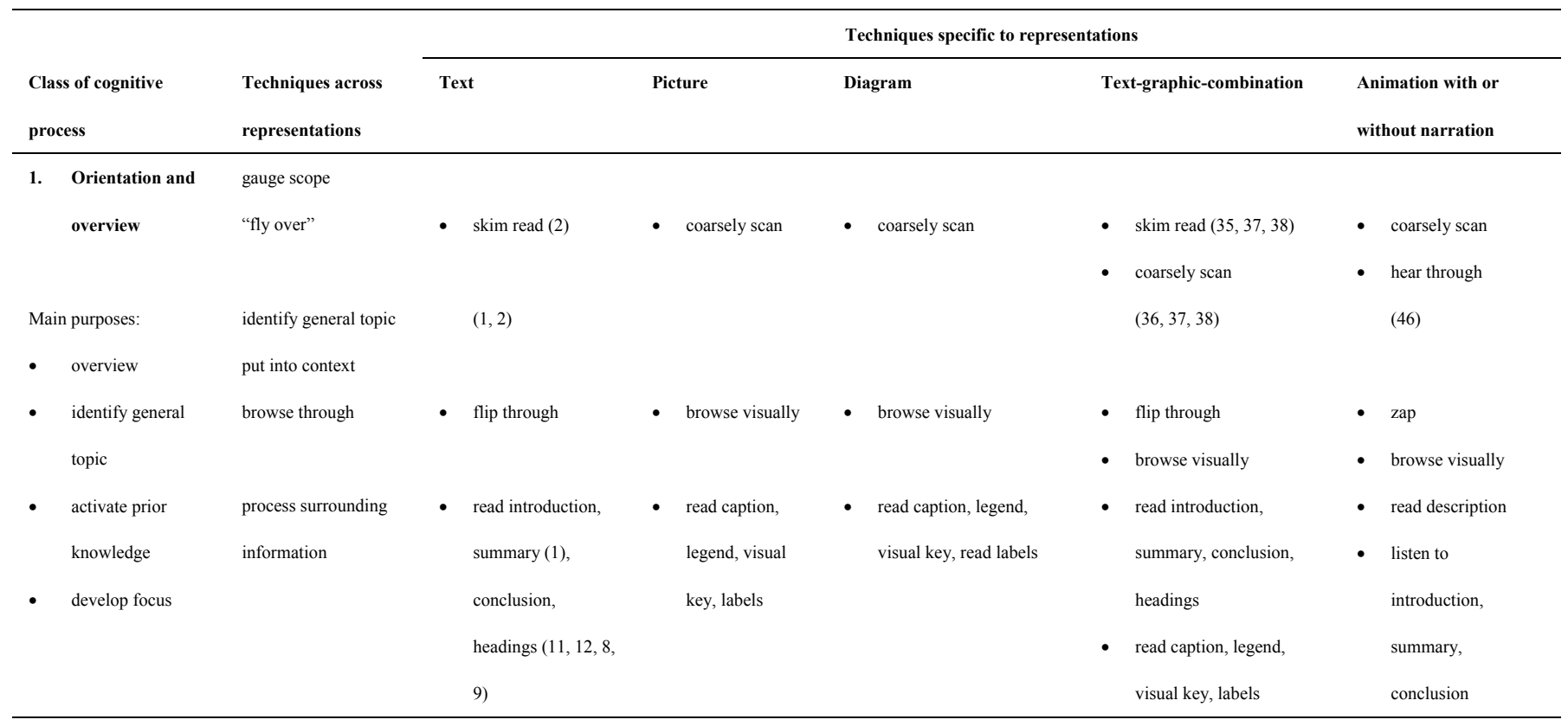


- read labels

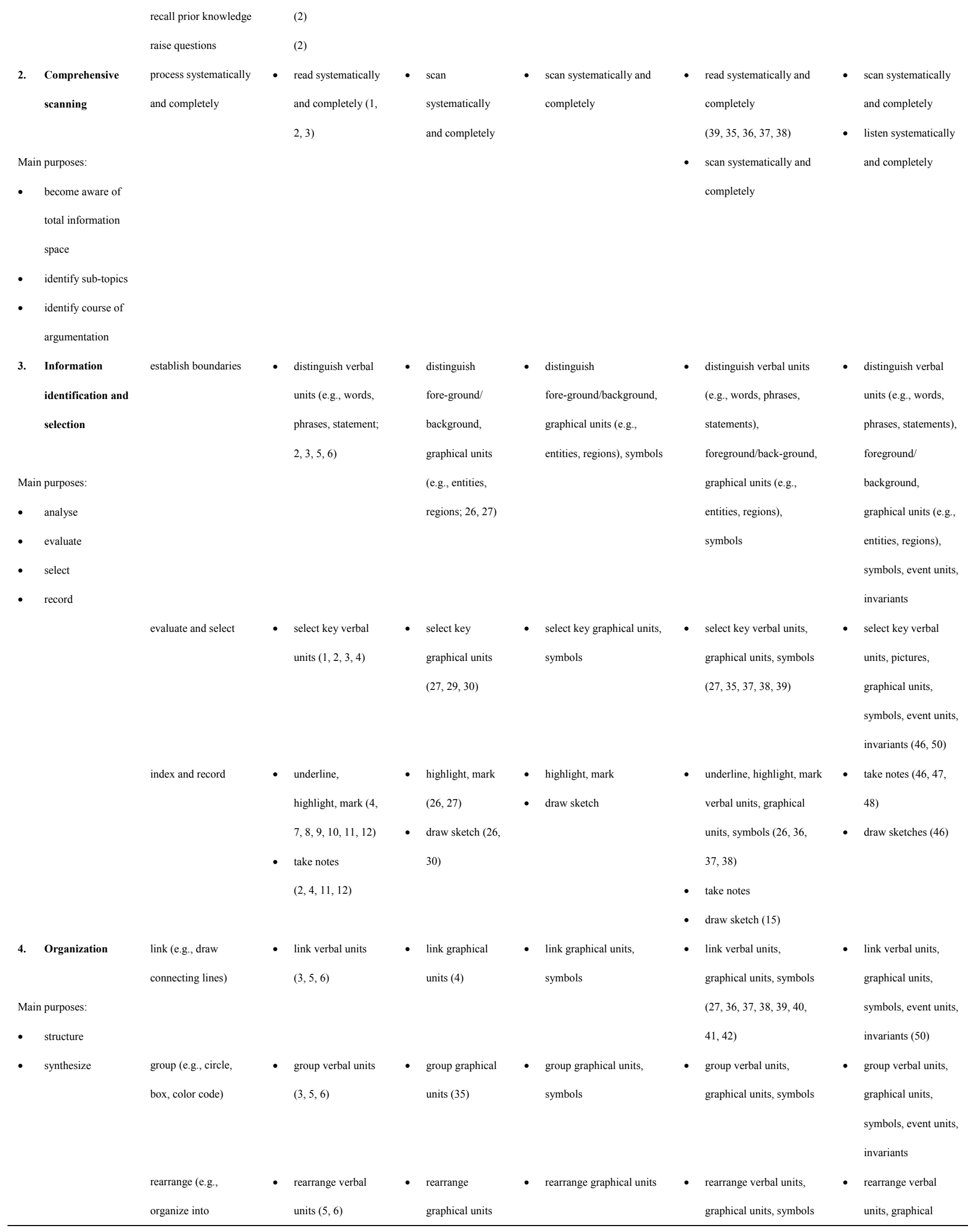


sequence, table,

hierarchy)

create higher order units

denote

5. Integration,

transformation,

and elaboration

Main purposes:

- $\quad$ interpret

- $\quad$ abstract

- $\quad$ exemplify

- justify

- $\quad$ appropriate
(35)

units, symbols, event

units, invariants (49)

- establish sections

- establish regions - establish regions

(3)

(35)

- introduce labels

- introduce headings

- introduce labels

(4)

$$
(4,15,26,31 \text {, }
$$

$33,32)$

$\bullet \quad$ introduce labels
$(15,31)$

- denote verbal units and

denote verbal units

and relations

- denote graphical

- denote graphical units,

between them $(2,5$,

6)

units and

symbols and relations

between them

relations

between them

(26)

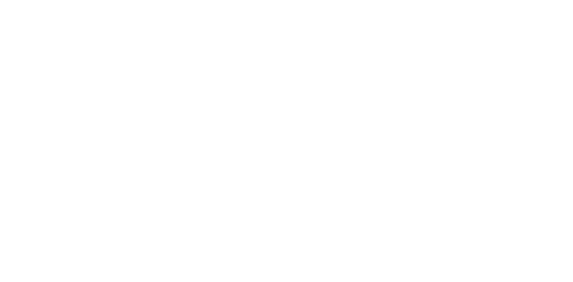

\begin{tabular}{|c|c|}
\hline relations between them & units, scenes and \\
\hline$(39,41,44)$ & relations between \\
\hline denote graphical units, & them \\
\hline symbols and relations & denote verbal units \\
\hline between them $(39,41$, & and relations \\
\hline 44) & between them \\
\hline denote relations between & denote relations \\
\hline verbal units, graphical & between verbal \\
\hline units and symbols (39, & units, graphical units \\
\hline 31,41 , & and scenes (46) \\
\hline
\end{tabular}

relations between them

- establish scenes

- establish regions in pictures

- establish sections in narration

- introduce headings

- $\quad$ introduce labels (46)

- denote graphical abstract
exemplify
self-explain
relate to prior
knowledge
appropriate

(2)

- $\quad$ Find examples (2)

- Explain text to yourself $(3,13)$

(2) 


\section{Aligning Strategies with and Constructing Strategies from the Systematic Characterization}

In this section, we first show how two existing strategies fit into the systematic characterization: (1) the PQ4R-Method of Thomas and Robinson (1972) for learning from text and (2) the strategy for learning from illustrated text proposed by Schlag and Ploetzner (2009, 2011). Although the learning techniques employed in both strategies are already mentioned in Table 1 (cf. the index 2 for Thomas \& Robinson, 1972, and the indexes 37 and 38 for Schlag \& Ploetzner, 2009, 2011), the table presents this information in a rather distributed way. Therefore, in Table 2 the component techniques of the selected strategies as well as their associated classes of cognitive processes are treated in a more compact way. Next, we exemplify how the systematic characterization of cognitive learning techniques can be aligned with the Animation Process Model of Lowe and Boucheix (2008) to generate a new strategy for learning from animation.

Table 2. How two existing learning strategies fit into the systematic characterization of cognitive learning techniques and what a new learning strategy could look like

\begin{tabular}{|c|c|c|c|}
\hline & Text & Illustrated text & $\begin{array}{l}\text { Animation without } \\
\text { narration }\end{array}$ \\
\hline $\begin{array}{l}\text { Class of cognitive } \\
\text { process }\end{array}$ & $\begin{array}{l}\text { Thomas and Robinson } \\
\text { (1972, PQ4R) }\end{array}$ & $\begin{array}{l}\text { Schlag and Ploetzner } \\
(2009,2011)\end{array}$ & $\begin{array}{l}\text { Based on Lowe and } \\
\text { Boucheix }(2008,2011)\end{array}$ \\
\hline $\begin{array}{l}\text { 1. Orientation and } \\
\text { overview }\end{array}$ & $\begin{array}{ll} & \text { skim read } \\
\text { - } & \text { identify general topic } \\
\text { - } & \text { recall prior } \\
& \text { knowledge } \\
\text { - } & \text { raise questions }\end{array}$ & $\begin{array}{ll}- & \text { skim read } \\
\text { - } & \text { coarsely scan }\end{array}$ & \\
\hline $\begin{array}{l}\text { 2. Comprehensive } \\
\text { scanning }\end{array}$ & 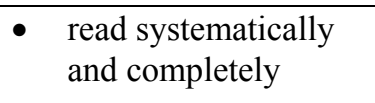 & $\begin{array}{l}\text { - read systematically } \\
\text { and completely }\end{array}$ & $\begin{array}{l}\text { - } \quad \text { scan systematically } \\
\text { and completely }\end{array}$ \\
\hline $\begin{array}{l}\text { 3. Information } \\
\text { identification and } \\
\text { selection }\end{array}$ & $\begin{array}{ll}\text { - } & \text { distinguish verbal } \\
\text { units } \\
\text { - } & \text { select key verbal } \\
\text { - } & \text { units } \\
\text { take notes }\end{array}$ & $\begin{array}{ll}\text { - } & \text { select key verbal } \\
\text { units } \\
\text { - } & \text { select key graphical } \\
\text { units } \\
\text { - } \\
\text { underline, highlight, } \\
\text { mark key verbal } \\
\text { units } \\
\text { highlight, mark key } \\
\text { graphical units }\end{array}$ & $\begin{array}{ll}\text { - } & \text { distinguish entities } \\
\text { - } & \text { distinguish event } \\
\text { units }\end{array}$ \\
\hline 4. Organization & & $\begin{array}{l}\text { - link verbal and } \\
\text { graphical units }\end{array}$ & - group event units \\
\hline $\begin{array}{l}\text { 5. Integration, } \\
\text { transformation and } \\
\text { elaboration }\end{array}$ & $\begin{array}{ll}\text { - } & \text { denote verbal units } \\
\text { and relations } \\
\text { between them } \\
\text { - } \quad \text { find examples } \\
\text { - } \quad \text { relate to prior } \\
\text { knowledge } \\
\text { - } \quad \text { state in own words } \\
\text { - } \quad \text { write summary }\end{array}$ & $\begin{array}{ll}\text { - } & \text { visualize text } \\
\text { - } & \text { verbalize picture } \\
\text { - } & \text { write summary }\end{array}$ & $\begin{array}{ll}\text { - } & \text { denote relations } \\
& \text { between event units } \\
\text { - } & \text { self-explain } \\
\text { - } & \text { write summary }\end{array}$ \\
\hline
\end{tabular}

6. Rehearsal

Thomas and Robinson's (1972) PQ4R-Method (Preview, Question, Read, Reflect, Recite, Review) structures learning from text by means of six steps. In the first step (Preview), the material is surveyed to get a general overview. Previewing takes advantage of various learning techniques such as skimming the text, identifying the general topic, and activating prior-knowledge. In the second step (Question), questions about the different sections of the text are formulated. In the third step (Read), the text is read systematically and completely. While 
reading the text thoroughly, learning techniques such as identifying key words and key phrases as well as taking notes are utilized. This step can both lead to answers to some of the previously raised questions and give rise to new ones. Step four (Reflect) and step five (Recite) target the construction of meaning. Within these steps, learning techniques such as establishing relations between units of presented information as well as between units of presented information and prior knowledge are employed. Step six (Review) serves to evaluate and to foster the understanding gained. It encourages the formulation of an overall summary as well as the provision of answers to the questions previously raised. The text is re-read only if necessary.

Although the PQ4R-Method does not employ techniques that explicitly encourage processes of information organization as conceptualized in Table 1, it nevertheless becomes evident from Table 2 that the PQ4R-Method focuses on encouraging a deep level approach to learning (cf. Marton \& Säljö, 1984). Techniques targeting the rehearsal of information are deliberately avoided in this method.

On the basis of current theories of multimedia learning (cf. Mayer, 2009; Schnotz \& Bannert, 2003), Schlag and Ploetzner $(2009,2011)$ proposed and empirically evaluated a four-step strategy for learning from illustrated text. The aim of the first step is to provide a general overview. It employs the learning techniques of skim reading the text and coarsely scanning the illustrations. The second step focuses on establishing relations between the text and the illustrations. It encourages students to read the text thoroughly, to highlight key words and key phrases in the text, to highlight corresponding entities in the illustrations, and - as far as possible - to label the graphical entities by using the key words and key phrases thereby linking both representations. In the third step, the students are asked to describe the identified relations between the text and the illustrations in their own words by writing a summary. The fourth step also encourages students to summarize the most important information visually by drawing a sketch of their own.

As with the PQ4R-Method of Thomas and Robinson (1972), the learning strategy proposed by Schlag and Ploetzner $(2009,2011)$ promotes a deep level approach to learning. While it focuses on establishing meaningful relations between text and illustrations, it does not put the same emphasis on the processing of the individual representations themselves. With respect to the processing of text, the strategy could be made more comprehensive by complementing it with techniques taken from established strategies for learning from text such as the PQ4R-Method. Regarding the processing of illustrations, however, we are not aware of learning strategies from which complementary techniques could be drawn. This lack of research on techniques and strategies for learning from pictorial representations becomes even more evident if learning from dynamic representations such as animations is considered.

Kombartzky et al. (2010) proposed and evaluated a strategy for learning from narrated animations. As is the case with the strategy for learning from illustrated texts by Schlag and Ploetzner $(2009,2011)$, this narrated animation strategy was aligned with current theories of multimedia learning (Mayer, 2009; Schnotz and Bannert, 2003). Because we are not aware of any strategy for learning from animations without narration, we chose this type of representation to exemplify how the systematic characterization of learning techniques could be used to generate a new strategy. We chose the Animation Processing Model (APM) by Lowe and Boucheix $(2008,2011)$ as our theoretical basis because current theories of multimedia learning do not provide a detailed account of how learners process the spatial and temporal characteristics of animations.

Based on the systematic characterization of cognitive learning techniques, Table 2 shows an example of a sequence of techniques that aim to induce the processes posited in the APM. Initially, the students are encouraged to scan the animation systematically and completely thereby identifying local events (localized perceptual exploration). Thereafter, the students are asked to group adjacent local events (regional structure formation). Next, the students need to establish causal relations between groups of events (global characterization). Afterwards the students are prompted to explain the functional purpose of each causal relation (functional differentiation). Finally, the students are asked to summarize the rules that underlie the displayed processes (mental model consolidation).

Once more Table 2 reveals that the proposed strategy encourages a deep level approach to learning. Because the strategy is made up of only six learning techniques, it is a promising candidate for successful pedagogical intervention from a practical point of view. That is, teachers would have to describe, explain, and demonstrate only few techniques and students would have to internalize and exercise only a small number of techniques. However, whether the strategy actually benefits learning is of course an open question. To answer this question, empirical research is required. 


\section{Discussion}

This paper has presented a systematic characterization of cognitive techniques for learning from textual and pictorial representations. It aims to bring a measure of coherence to research that is currently distinguished by fragmentation, inconsistencies, and omissions. We showed that the characterization is consistent with established strategies for learning from either a single type of representation (e.g., text) or combined representations (e.g., illustrated texts). The characterization was also used to demonstrate how new learning strategies can be generated from theoretical accounts of how a particular type of representation is processed (e.g., un-narrated animation).

Our analyses highlight deficits in current research on learning, especially with regard to pictorial representations. While in recent years much research has been conducted on improving the design of static and dynamic pictorial representations, this has not been matched by a corresponding level of investigation into cognitive techniques and strategies for learning from static and dynamic pictorial representations. However, well-designed pictorial representations of themselves are no guarantee of successful learning. Further, students will not always be presented with pictorial representations that are designed in an optimal way. Without suitable cognitive techniques and strategies for handling these representations effectively, learning is likely to be compromised.

In the light of rapid growth in the quantity and variety of static and dynamic pictorial representations in learning material, far more research on cognitive techniques and strategies for learning from pictorial representations is required. Such research needs to encompass (a) further investigations of how static and dynamic representations are processed by students, (b) theory-driven conceptualization and empirical evaluation of techniques and strategies for learning from pictorial representations, and (c) the practical integration of empirically validated techniques and strategies into teaching practices.

Current theories and models of how static and dynamic pictorial representations are processed by students (for an overview see Anglin, Vaez \& Cunningham, 2003) form a promising starting point for conceptualizing learning techniques and strategies. For example, as described earlier, the APM (Lowe \& Boucheix, 2008) characterizes learning from animation in terms of five processing phases with a progression from bottom-up to top-down processes: (1) localized perceptual exploration, (2) regional structure formation, (3) global characterization, (4) functional differentiation, and (5) mental model consolidation.

Unlike other theories and models that deal with learning from pictorial representations such as Richard Mayer's Cognitive Theory of Multimedia Learning (Mayer, 2009, 2005b), the APM explicitly takes account of properties that are specific to dynamic pictorial representations such as animations. However, whereas the APM constitutes a theoretical abstraction, a learning strategy corresponds to a specific pedagogical intervention. That is, the generation of a learning strategy requires the formulation of a particular sequence of distinctive techniques that students actually can apply either mentally or externally. Because a theoretical abstraction is always underdetermined with respect to a specific pedagogical intervention, the APM - like any other model of learning - cannot directly be mapped to a learning strategy. Therefore, as in the research conducted by Thomas and Robinson (1972) as well as by Schlag and Ploetzner (2009, 2010), learning techniques need to be specified that are suitable to induce the cognitive processes considered to be relevant in the underlying process model.

As demonstrated by the gaps for the un-narrated animation example in Table 2, the characterization can highlight interesting possibilities that have not previously been considered. For example, it may be that the blank 'Orientation and overview' cell for this type of representation suggests the APM could be elaborated to cover cases in which the learner is allowed more than a single pass through an animation. Further, deficiencies such as the present lack of techniques for easy learner identification and selection of graphic units within an animation could be addressed using technological innovations such as touch tablets. One possibility here would be for a learner to tag a target entity by briefly touching it and for the tagged entity to then remain highlighted throughout the animation's time course. Singling out two or more entities in this way would allow not only the entities to be followed more readily, but also their relationships over time. Given that most existing learning techniques that address materials that contain pictures target relations between different types of representations, perhaps more techniques are needed that help learners process relations within a single representation, such as an un-narrated animation.

Many of the techniques that comprise text processing strategies were derived from the findings of research comparing successful and less successful readers. The present relative lack of techniques for learning from static pictures and particularly animations could perhaps be addressed by building up a corresponding body of comparative research for these representations. However, the way animations are presented must also give learners the opportunity to apply effective techniques. As noted by Winn (1993), attentive processing takes 
considerably longer than pre-attentive processing and the transitory nature of animation may preclude application of such techniques if learners are allowed only a single exposure to the available information.

In the longer term, research needs not only to provide conceptualizations and evaluations of techniques and strategies for learning from different pictorial representations. These techniques and strategies also need to be structured into coherent approaches to learning. Which techniques apply to a range of representations and which techniques are specific to certain representations? To what extent is it possible to order learning techniques sequentially and hierarchically?

Besides revealing that cognitive techniques for learning from pictorial representations require more research, the systematic characterization of learning techniques provided in Table 1 is an important first step in the construction of such a structure. The characterization describes which learning techniques might be recruited to induce specific cognitive processes when learning from particular representations. Because the characterization is systematic, it helps to identify learning techniques that can be applied to a range of representations as well as learning techniques that are specific to particular representations. Furthermore, the characterization supports the construction of new learning strategies that combine different learning techniques across the classes of cognitive processes.

It is when students are equipped with a structured inventory of learning techniques that learning from textual and pictorial representations can become truly strategic. To be successful learners in the world of increasingly diverse representations, they must be able to identify relevant properties of representations and to appropriately select and combine techniques that take these properties into account during learning.

\section{References}

Ainsworth, S., \& Loizou, A. (2003). The effects of self-explaining when learning with text or diagrams. Cognitive Science, 27, 669-681. $\quad$ Retrieved from http://csjarchive.cogsci.rpi.edu/2003v27/i04/p0669p0681/00000126.pdf

Anglin, G. J., Vaez, H., \& Cunningham, K. L. (2003). Visual representation and learning: The role of static and animated graphics. In D. H. Jonassen (Ed.), Handbook of research on educational communications and technology (2nd ed., pp. 865-916). Mahwah, NJ: Lawrence Erlbaum Associates.

Artelt, C. (2000). Strategisches Lernen [Strategical learning]. Münster: Waxmann Verlag.

Atkinson, R. K., Levin, J. R., Kiewra, K. A., Meyers, T., Kim, S., Atkinson, L. A., Renandya, W. A., \& Hwang, Y. (1999). Matrix and mnemonic text-processing adjuncts: Comparing and combining their components. Journal of Educational Psychology, 91(2), 342-357. http://dx.doi.org/10.1037/0022-0663.91.2.342

Ballstaedt, S.-P. (2006). Zusammenfassen von Textinformationen [Summarizing text information]. In H. Mandl \& H. F. Friedrich (Eds.), Handbuch Lernstrategien [Handbook of learning strategies] (pp. 117-126). Göttingen: Hogrefe Verlag.

Bannert, M., \& Schnotz, W. (2006). Vorstellungsbilder und Imagery-Strategien [Imagery pictures and imagery strategies]. In H. Mandl, \& H. F. Friedrich (Eds.), Handbuch Lernstrategien [Handbook of learning strategies] (pp. 72-88). Göttingen: Hogrefe Verlag.

Bartholomé, T. (2007). Kohärenzbildung beim Wissenserwerb mit Text und Bild. Wie können Lerner unterstützt werden? [Coherence formation during knowledge acquisition from text and picture. How can learners be supported?]. Berlin: Logos.

Bodemer, D., Ploetzner, R., Feuerlein, I., \& Spada, H. (2004). The active integration of information during learning with dynamic and interactive visualisations. Learning and Instruction, 14, 325-341.

Brünken, R., Seufert, T., \& Zander, S. (2005). Förderung der Kohärenzbildung beim Lernen mit multiplen Repräsentationen [Fostering of coherence formation when learning with multiple representations]. Zeitschrift für Pädagogische Psychologie, 19(1/2), 61-75. http://dx.doi.org/10.1024/1010-0652.19.12.61

Clark, R. C., \& Mayer, R. E. (2008). E-Learning and the science of instruction (2nd ed.). San Francisco, CA: Pfeiffer.

Dansereau, D. F., Collins, K. W., McDonald, B. A., Holley, C. D., Garland, J. C., Diekhoff, G., \& Evans, S. H. (1979). Development and evaluation of a learning strategy training program. Journal of Educational Psychology, 71, 64-73. http://dx.doi.org/10.1037/0022-0663.71.1.64

de Jong, T. (2005). The guided discovery principle in multimedia learning. In R. E. Mayer (Ed.), The Cambridge handbook of multimedia learning (pp. 215-228). New York: Cambridge University Press. 
de Koning, B. B., Tabbers, H. K., Rikers, R. M., \& Paas, F. G. W. C. (2010). Learning by generating vs. receiving instructional explanations: Two approaches to enhance attention cueing in animations. Computers \& Education, 55(2), 681-691. http://dx.doi.org/10.1016/j.compedu.2010.02.027

de Vries, E., \& Lowe, R. K. (2010). Graphicacy: What does the learner bring to a graphic? In F. Maes, K. Scheiter, \& A. Schüler (Eds.), Tracing the mind - How do we learn from text and graphics? Meeting of the EARLI Special Interest Group on Comprehension of Text and Graphics. Tübingen: Knowledge Media Research Center. Retrieved from http://www.earlisig2-2010.de/sig2-2010/downloads/SIG2_2010_Papers.zip

Dean, R. S., \& Kulhavy, R. W. (1981). Influence of spatial organization on prose learning. Journal of Educational Psychology, 73, 57-64. http://dx.doi.org/10.1037/0022-0663.73.1.57

Doelker, C. (1997). Ein Bild ist mehr als ein Bild. Visuelle Kompetenz in der Multimedia-Gesellschaft [A picture is more than a picture. Visual competence in the multimedia society]. Stuttgart: Klett-Cotta.

Dornisch, M., Sperling, R. A., \& Zeruth, J. A. (2011). The effects of levels of elaboration on learners' strategic processing of text. Instructional Science, 39, 1-26. http://dx.doi.org/10.1007/s11251-009-9111-z

Drewniak, U. (1992). Lernen mit Bildern in Texten [Learning with pictures in texts]. Münster: Waxmann Verlag.

Friedrich, H. F. (1992). Vermittlung von reduktiven Textverarbeitungsstrategien durch Selbstinstruktion [Acquistion of reductive text comprehension strategies by means of self-instruction]. In H. Mandl, \& H. F. Friedrich (Eds.), Lern- und Denkstrategien [Learning and thinking strategies] (pp. 193-212). Göttingen: Hogrefe Verlag.

Friedrich, H. F. (1995). Training und Transfer reduktiver-organisierender Strategien für das Lernen mit Texten. [Training and transfer of reductive and organisational strategies for learning from texts]. Münster, Germany: Aschendorff.

Friedrich, H. F., \& Ballstaedt, S.-P. (1997). Strategien für das Lernen mit Medien [Strategies for learning from media]. In H. Felix, G. Eigler, H. Mandl, W. Schnotz, F. Schott, \& N. M. Seel (Ed.), Multimediale Lernumgebungen in der betrieblichen Weiterbildung [Multimedia learning environments in professional training] (pp. 165-265). Neuwied: Luchterhand.

Gambrell, L. B., \& Jawitz, P. B. (1993). Mental imagery, text illustrations, and children's story comprehension and recall. Reading Research Quarterly, 28, 264-276.

Gambrell, L. B., Morrow, L. M., \& Pressley, M. (2007). Best practices in literacy instruction (3rd ed.). New York: Guilford Press.

Gane, B. D., \& Catrambone, R. (2006). Give learners questions to answer while they watch animated examples. In S. A. Barab, K. E. Hay, \& D. T. Hickey (Eds.), Proceedings of the Seventh International Conference on the Learning Sciences (pp. 922-923). Mahwah, NJ: Lawrence Erlbaum Associates.

Graves, A. W., \& Levin, J. R. (1989). Comparison of monitoring and mnemonic text-processing strategies in learning disabled students. Learning Disability Quarterly, 12(3), 232-236.

Hall, V. C., Bailey, J., \& Tillmann, C. (1997). Can student-generated illustrations be worth ten-thousand words? Journal of Educational Psychology, 89, 677-681. http://dx.doi.org/10.1037/0022-0663.89.4.677

Hamilton, R. J. (1997). Effects of three types of elaboration on learning concepts from text. Contemporary Educational Psychology, 22, 299-318. http://dx.doi.org/10.1006/ceps.1997.0935

Hartley, J. T., Harker, J. O., \& Walsh, D. A. (1980). Contemporary issues and new directions in adult development of learning and memory. In L. W. Poon (Ed.), Aging in the 1980's: Psychological issues (pp. 239-252). Washington, DC: American Psychological Association.

Hasselhorn, M., \& Körkel, J. (1986). Metacognitive versus traditional reading instructions: The mediating role of domain-specific knowledge on children's text processing. Human Learning, 5, 75-90.

Hasselhorn, M., \& Körkel, J. (1983). Gezielte Förderung der Lernkompetenz am Beispiel der Textverarbeitung [Systematic facilitation of the competence to learn - The example of text processing]. Unterrichtswissenschaft, 4, 370-382.

Hegarty, M., Kriz, S., \& Cate, C. (2003). The roles of mental animations and external animations in understanding mechanical systems. Cognition and Instruction, 21, 325-360. http://dx.doi.org/10.1207/s1532690xci2104_1 
Huk, T., \& Ludwigs, S. (2009). Combining cognitive and affective support in order to promote learning. Learning and Instruction, 19, 495-505. http://dx.doi.org/10.1016/j.learninstruc.2008.09.001

Kintsch, W. (1998). Comprehension - A paradigm for cognition. New York: Cambridge University Press.

Kintsch, W., \& van Dijk, T. A. (1978). Toward a model of text comprehension and production. Psychological Review, 85(5), 363-394. http://dx.doi.org/10.1037/0033-295X.85.5.363

Kombartzky, U., Ploetzner, R., Schlag, S., \& Metz, B. (2010). Developing and evaluating a strategy for learning from animation. Learning and Instruction, 20, 424-433. http://dx.doi.org/10.1016/j.learninstruc.2009.05.002

Kremling, C. (2008). "Lehren und Lernen mit Bildern" - Erste Ergebnisse der Eingangserhebung des Forschungsprojektes "Bildliteralität und ästhetische Alphabetisierung" ["Teaching and Learning with pictures" - First results of a survey within the research project "Picture literacy and aesthetical alphabetization"]. In G. Lieber (Ed.), Lehren und Lernen mit Bildern [Teaching and learning with pictures] (pp. 115-123). Hohengehren: Schneider Verlag.

Kress, G. (2003). Literacy in the new media age. New York: Routledge.

Kress, G., \& van Leeuwen, T. (2006). Reading images - The grammar of visual design (2nd ed.). New York: Routledge.

Kriz, S., \& Hegarty, M. (2007). Top-down and bottom-up influences on learning from animations. International Journal of Human Computer Studies, 65(11), 911-930. http://dx.doi.org/10.1016/j.ijhcs.2007.06.005

Larson, C. O., Dansereau, D. F., Hythecker, V. I., O'Donell, A., Young, M. D., Lambiotte, J. G., \& Rocklin, T. R. (1986). Technical training: An application of a strategy for learning structural and functional information. Contemporary Educational Psychology, 11, 217-228. http://dx.doi.org/10.1016/0361-476X(86)90018-4

Leopold, C. (2009). Lernstrategien und Textverstehen [Learning strategies and text comprehension]. Münster: Waxmann Verlag.

Leutner, D., \& Leopold, C. (2003). Selbstreguliertes Lernen als Selbstregulation von Lernstrategien [Self regulated learning as self regulation of learning strategies]. Unterrichtswissenschaft, 31(1), 38-56. http://www.digizeitschriften.de/dms/resolveppn/?PPN=PPN513613439_0031

Leutner, D., Leopold, C., \& den Elzen-Rump, V. (2007). Self-regulated learning with a text-highlighting strategy: A training experiment. Zeitschrift für Psychologie, 215, 174-182. http://dx.doi.org/10.1027/0044-3409.215.3.174

Lieber, G. (Ed.). (2008). Lehren und Lernen mit Bildern [Teaching and learning with pictures]. Hohengehren: Schneider Verlag.

Lowe, R. K. (1999). Extracting information from an animation during complex visual learning. European Journal of Psychology of Education, 14(2), 225-244. http://dx.doi.org/10.1007/BF03172967

Lowe, R. K. (2003). Animation and learning: Selective processing of information in dynamic graphics. Learning and Instruction, 13(2), 157-176. http://dx.doi.org/10.1016/S0959-4752(02)00018-X

Lowe, R. K. (2004). Interrogation of a dynamic visualization during learning. Learning and Instruction, 14(3), 257-274. http://dx.doi.org/10.1016/j.learninstruc.2004.06.003

Lowe, R. K. (2008). Learning from animation: Where to look, when to look. In R. K. Lowe \& W. Schnotz (Eds.), Learning with animation - Research implications for design (pp. 49-68). New York: Cambridge University Press.

Lowe, R., \& Boucheix, J.-M. (2008). Learning from animated diagrams: How are mental models built? In G. Stapleton, J. Howse, \& J. Lee (Eds.), Diagrammatic representations and inference - Proceedings of the Fifth International Conference Diagrams 2008 (pp. 266-281). Berlin: Springer Publishers.

Lowe, R., \& Boucheix, J.-M. (2011). Cueing complex animations: Does direction of attention foster learning processes? Learning and Instruction, 21, 650-663. http://dx.doi.org/10.1016/j.learninstruc.2011.02.002

Mandl, H., \& Friedrich, H. F. (Eds.). (1992). Lern- und Denkstrategien [Learning and thinking strategies]. Göttingen: Hogrefe Verlag.

Mandl, H., \& Friedrich, H. F. (Eds.). (2006). Handbuch Lernstrategien [Handbook of learning strategies]. Göttingen: Hogrefe Verlag. 
Marton, F., \& Säljö, R. (1984). Approaches to learning. In F. Marton, D. J. Hounsell, \& N. Entwistle (Eds.), The experience of learning (pp. 39-58). Edinburgh: Scottish Academic Press.

Mayer, R. E. (2005b). Cognitive theory of multimedia learning. In R. E. Mayer (Ed.), The Cambridge handbook of multimedia learning (pp. 31-48). New York: Cambridge University Press.

Mayer, R. E. (2009). Multimedia learning (2nd ed.). New York: Cambridge University Press.

Mayer, R. E. (Ed.). (2005a). The Cambridge handbook of multimedia learning. New York: Cambridge University Press.

Metz, B., \& Wichert, A. (2009). Lernen mit illustrierten Texten [Learning from illustrated texts]. In R. Ploetzner, T. Leuders, \& A. Wichert (Eds.), Lernchance Computer - Strategien für das Lernen mit digitalen Medienverbünden [The computer as an opportunity for learning - Strategies for learning from digital media] (pp. 141-161). Münster: Waxmann Verlag.

Moreno, R., \& Valdez, A. (2005). Cognitive load and learning effects of having students organize pictures and words in multimedia environments: The Role of student interactivity and feedback. Educational Technology Research and Development, 53(3), 35-45. http://dx.doi.org/10.1007/BF02504796

OECD (Ed.). (2000). Literacy in the information age - Final report of the international adult literacy survey. Paris: Organisation for Economic Co-operation and Development. Retrieved from http://www.oecd.org/education/country-studies/39437980.pdf

Paas, F. G. W. C., van Gerven, P. W., \& Wouters, P. (2007). Instructional efficiency of animation: Effects of interactivity through mental reconstruction of static key frames. Applied Cognitive Psychology, 21(6), 783-793. http://dx.doi.org/10.1002/acp.1349

Pask, G. (1976). Styles and strategies of learning. British Journal of Educational Psychology, 81, 33-40. http://dx.doi.org/10.1111/j.2044-8279.1976.tb02305.x

Peeck, J. (1993). Increasing picture effects in learning from illustrated text. Learning and Instruction, 3, 227-238. http://dx.doi.org/10.1016/0959-4752(93)90006-L

Peeck, J. (1994). Enhancing graphic-effects in instructional texts: Influencing learning activities. In W. Schnotz, \& R. W. Kulhavy (Eds.), Comprehension of graphics (pp. 291-302). Amsterdam: Elsevier.

Pettersson, R. (2008). Aspekte der Verwendung von Bildern in Lehrbüchern [Aspects of the use of pictures in textbooks]. In G. Lieber (Ed.), Lehren und Lernen mit Bildern [Teaching and learning with pictures] (pp. 134-145). Hohengehren: Schneider Verlag.

Phillipp, J. (2008). Förderung des Verstehens von Liniendiagrammen durch interpretierende und konstruierende Lernhandlungen [Facilitating understanding of line diagrams by interpretative and constructive learning activities] (Doctoral Thesis). Freiburg: Albert-Ludwigs-Universität Freiburg.

Pinker, S. (1990). A theory of graph comprehension. In R. Freedle (Ed.), Artificial intelligence and the future of testing (pp. 73-126). Hillsdale, NJ: Lawrence Erlbaum Associates.

Ploetzner, R., Bodemer, D., \& Neudert, S. (2008). Successful and less successful use of dynamic visualisations in instructional texts. In R. K. Lowe, \& W. Schnotz (Eds.), Learning with animation: Research implications for design (pp. 71-91). New York: Cambridge University Press.

Ploetzner, R., Lippitsch, S., Galmbacher, M., Heuer, D., \& Scherrer, S. (2009). Students' difficulties in learning from dynamic visualisations and how they may be overcome. Computers in Human Behavior, 25, 56-65. http://dx.doi.org/10.1016/j.chb.2008.06.006

Pressley, M., \& Harris, K. R. (2006). Cognitive strategies instruction: From basic research to classroom instruction. In P. A. Alexander, \& P. H. Winne (Eds.), Handbook of educational psychology (pp. 265-286). Mahwah, NJ: Lawrence Erlbaum Associates.

Rasco, R. W., Tennyson, R. D., \& Boutwell, R. C. (1975). Imagery instructions and drawings in learning prose. Journal of Educational Psychology, 67(2), 188-192. http://dx.doi.org/10.1037/h0077014

Robinson, F. P. (1946). Effective study. New York: Harper and Row.

Rummel, N., Levin, J.-R., \& Woodward, M.-M. (2003). Do pictorial mnemonic text-learning aids give students something worth. Journal of Educational Psychology, 95(2), 327-334. http://dx.doi.org/10.1037/0022-0663.95.2.327 
Salomon, G. (1983). The differential investment of mental effort in learning from different sources. Educational Psychologist, 18(1), 42-50. http://dx.doi.org/10.1080/00461528309529260

Salomon, G. (1984). Television is easy and print is tough: The differential investment of mental effort in learning as a function of perceptions and attributions. Journal of Educational Psychology, 76, 647-658. http://dx.doi.org/10.1037/0022-0663.76.4.647

Schlag, S., \& Ploetzner, R. (2009). Lernen mit informierenden Bildern in Texten [Learning from informational pictures in texts]. In R. Ploetzner, T. Leuders, \& A. Wichert (Eds.), Lernchance Computer - Strategien für das Lernen mit digitalen Medienverbünden [The computer as an opportunity for learning - Strategies for learning from digital media] (pp. 123-140). Münster: Waxmann Verlag.

Schlag, S., \& Ploetzner, R. (2011). Supporting learning from illustrated texts: Conceptualizing and evaluating a learning strategy. Instructional Science, 39, 921-937. http://dx.doi.org/10.1007/s11251-010-9160-3

Schlag, S., Florax, M., \& Ploetzner, R. (2007). The use of learning strategies in learning from text and pictures. In T. Hirashima, H. U. Hoppe, \& S. S.-C. Young (Eds.), Supporting learning flow through integrative technologies - Proceedings of the 15th International Conference of Computers in Education (pp. 331-338). Amsterdam: IOS Press.

Schmidt-Weigand, F. (2005). Dynamic visualizations in multimedia learning: The influence of verbal explanations on visual attention, cognitive load and learning outcome (Doctoral Thesis). Gießen: Justus Liebig Universität.

Schnotz, W. (2001). Sign systems, technologies, and the acquisition of knowledge. In J. F. Rouet, J. Levonen, \& A. Biardeau (Eds.), Multimedia learning - Cognitive and instructional issues (pp. 9-29). Amsterdam: Elsevier.

Schnotz, W. (2005). An integrated model of text and picture comprehension. In R. E. Mayer (Ed.), The Cambridge handbook of multimedia learning (pp. 49-69). New York: Cambridge University Press.

Schnotz, W., \& Bannert, M. (2003). Construction and interference in learning from multiple representations. Learning and Instruction, 13(2), 141-156. http://dx.doi.org/10.1016/S0959-4752(02)00017-8

Seufert T. (2009). Lernen mit multiplen Repräsentationen: Gestaltungs- und Verarbeitungsstrategien [Learning from multiple representations: Strategies for design and processing]. In R. Ploetzner, T. Leuders, \& A. Wichert (Eds.), Lernchance Computer - Strategien für das Lernen mit digitalen Medienverbünden [The computer as an opportunity for learning - Strategies for learning from digital media] (pp. 45-66). Münster: Waxmann Verlag.

Seufert, T. (2003). Supporting coherence formation in learning from multiple representations. Learning and Instruction, 13, 227-237. http://dx.doi.org/10.1016/S0959-4752(02)00022-1

Seufert, T., Zander, S., \& Brünken, R. (2007). Das Generieren von Bildern als Verstehenshilfe beim Lernen aus Texten [The production of pictures as an aid for understanding texts]. Zeitschrift für $\begin{array}{llll}\text { Entwicklungspsychologie und Pädagogische } \quad \text { Psychologie, } & 39(1), \quad 33-42 .\end{array}$ http://dx.doi.org/10.1026/0049-8637.39.1.33

Souvignier, E., Küppers, J., \& Gold, A. (2003a). Wir werden Textdetektive. Beschreibung eines Unterrichtsprogramms zur Förderung des Leseverstehens [We become text detectives. Description of a program for facilitating text comprehension]. Didaktik Deutsch, 14, 21-37.

Souvignier, E., Küppers, J., \& Gold, A. (2003b). Lesestrategien im Unterricht: Einführung eines Programms zur Förderung des Textverstehens in 5. Klassen [Reading strategies in the classroom: Introduction to a program for facilitating text comprehension in grade five]. Unterrichtswissenschaft, 31, 166-183. $\mathrm{http}: / /$ www.digizeitschriften.de/dms/resolveppn/?PPN=PPN513613439_0031

Stern, E., Aprea, C., \& Ebner, H. G. (2003). Improving cross-content transfer in text processing by means of active graphical representation. Learning and Instruction, 13, 191-203. http://dx.doi.org/10.1016/S0959-4752(02)00020-8

Streblow, L., \& Schiefele, U. (2006). Lernstrategien im Studium [Learning strategies in academic studies]. In H. Mandl, \& H. F. Friedrich (Eds.), Handbuch Lernstrategien [Handbook of learning strategies] (pp. 352-364). Göttingen: Hogrefe Verlag.

Street, B. V. (1984). Literacy in theory and practice. New York: Cambridge University Press. 
Svensson, L. (1977). On qualitative differences in learning, III: Study skill and learning. British Journal of Educational Psychology, 47, 233-243. http://dx.doi.org/10.1111/j.2044-8279.1977.tb02352.x

Thomas, E. L., \& Robinson, H. A. (1972). Improving reading in every class: A source-book for teachers. Boston, MA: Allyn and Bacon.

van Meter, P., \& Garner, J. (2005). The promise and practice of learner-generated drawing: Literature review $\begin{array}{lllll}\text { and } & \text { Synthesis. Educational Psychology Review, 17(4), 285-325. }\end{array}$ http://dx.doi.org/10.1007/s10648-005-8136-3)

van Meter, P., Aleksic, M., Schwartz, A., \& Garner, J. (2006). Learner-generated drawing as a strategy for learning from content area text. Contemporary Educational Psychology, 31(2), 142-166. http://dx.doi.org/10.1016/j.cedpsych.2005.04.001

Weidenmann, B. (1988). Psychische Prozesse beim Verstehen von Bildern [Psychological processes when understanding pictures]. Bern: Huber Verlag.

Weidenmann, B. (1989). When good pictures fail: An information processing approach to the effect of illustration. In H. Mandl \& J. R. Levin (Eds.), Knowledge acquisition from text and pictures (pp. 157-170). Amsterdam: North-Holland.

Weidenmann, B. (1991). Lernen mit Bildmedien: Psychologische und didaktische Grundlagen [Learning from pictures: Psychological and pedagogical foundations]. Weinheim: Beltz.

Weidenmann, B. (1994). Wissenserwerb mit Bildern [Knowledge acquisition with pictures]. Göttingen: Huber.

Weidenmann, B. (2006). Lernen mit Medien [Learning from media]. In A. Krapp, \& B. Weidenmann (Eds.), Pädagogische Psychologie [Educational psychology] (5. Aufl., pp. 423-476). Weinheim: Psychologie Verlags Union.

Weinstein, C. E., \& Mayer, R. E. (1986). The teaching of learning strategies. In M. C. Wittrock (Ed.), Handbook of research on teaching (3rd ed., pp. 315-327). New York: MacMillan Publishers.

Winn, W. (1993). An account of how readers search for information in diagrams. Contemporary Educational Psychology, 18, 162-185. http://dx.doi.org/10.1006/ceps.1993.1016)

Wittrock, M. C. (1974). Learning as a generative process. Educational Psychologist, 11, 87-95. http://dx.doi.org/10.1080/00461527409529129

Wittrock, M. C. (1989). Generative processes of comprehension. Educational Psychologist, 24, 345-376. http://dx.doi.org/10.1207/s15326985ep2404_2 